Liver, Pancreas and Biliary Tract

\title{
Incidence, prevalence, and causes of death of patients with autoimmune hepatitis: A nationwide register-based cohort study in Finland 弥, 弥弥
}

\author{
Lauri Puustinen $^{a}{ }^{\text {, }}$, Nina Barner-Rasmussen ${ }^{a}$, Eero Pukkala ${ }^{b, c}$, Martti Färkkiläa \\ a Department of Gastroenterology, Helsinki University Hospital, Helsinki University, Helsinki, Finland \\ ${ }^{\mathrm{b}}$ Faculty of Social Sciences, University of Tampere, Tampere, Finland \\ ${ }^{\text {c } F i n n i s h ~ C a n c e r ~ R e g i s t r y, ~ I n s t i t u t e ~ f o r ~ S t a t i s t i c a l ~ a n d ~ E p i d e m i o l o g i c a l ~ C a n c e r ~ R e s e a r c h, ~ H e l s i n k i, ~ F i n l a n d ~}$
}

\section{A R T I C L E I N F O}

Article history:

Received 29 October 2018

Accepted 27 January 2019

Available online $\mathrm{xxx}$

\section{Keywords:}

Autoimmune liver disease

Epidemiology

Mortality

\begin{abstract}
A B S T R A C T
Background: Epidemiological studies of autoimmune hepatitis are scarce and often based on single centre registries.

Aims: We conducted a nationwide register study of incidence, prevalence, survival, and causes of death of autoimmune hepatitis patients in Finland.

Methods: Autoimmune hepatitis cases 1995-2015 were retrieved from the national database of special reimbursements for drugs costs. Data on causes of death were retrieved from Statistics Finland.

Results: After incomplete registration of AIH during the first years, the incidence of autoimmune hepatitis stabilised to $1.1 / 100,000$ person-years (1.6 in women and 0.52 in men) in 2008-2015. The prevalence of autoimmune hepatitis at the end of 2015 was 14.3/100,000, 23.0/100,000 in women and 6.6/100,000 in men. The all-cause standardized mortality ratio (SMR) of autoimmune hepatitis patients was 1.81 (95\% confidence interval (CI) 1.47-2.20). The SMR was increased in all age groups and in both sexes. The SMR for hepatocellular carcinoma was 20.6 (95\% CI 10.3-36.8), and for digestive diseases in overall 13.5 (95\% CI 8.2-20.8), constituting mainly from autoimmune hepatitis and liver cirrhosis.

Conclusion: Incidence of autoimmune hepatitis has remained stable, with clear female predominance. Autoimmune hepatitis is associated with a markedly increased risk of death with hepatocellular cancer forming the greatest risk.
\end{abstract}

(C) 2019 Editrice Gastroenterologica Italiana S.r.l. Published by Elsevier Ltd. All rights reserved.

\section{Lay summary}

Incidence and prevalence of autoimmune hepatitis is stable in Finland, based on nationwide medical registries. All-cause mortality is higher than in the normal population, and when compared to controls without autoimmune hepatitis, mainly due to considerable risk of hepatocellular carcinoma.

\section{Key summary}

Prior to this study, studies reporting incidence, prevalence, survival, and causes of death have been scarce.

\footnotetext{
㧒 The study has been supported by a grant received from Mary och Georg C. Ehrnrooth's foundation.

放 All authors have participated in study planning, data gathering, analysing the data and writing of the manuscript.

* Corresponding author at: Haartmaninkatu 4, Po box 340, FI-00280 Helsinki, Finland.

E-mail address: lauri.puustinen@helsinki.fi (L. Puustinen).
}

We report the second largest patient cohort of autoimmune hepatitis with the longest follow-up so far. Also, we report a different distribution of AIH than what has been previously reported. We also show, that increase in the risk of death is present already at the diagnosis of $\mathrm{AIH}$

\section{Introduction}

Autoimmune hepatitis ( $\mathrm{AIH})$ is a chronic liver disease characterized by interface hepatitis, rosette formation, plasma cell infiltration, and emperipolesis in histological examination, hypergammaglobulinemia and a selection of unspecific autoantibodies [1]. Incidence rates from 0.7 to 2.0 per 100,000 person-years have been reported previously with point prevalence from 8 to 42.9 per 100,000 population [2-11]. However, most of these studies have been performed based on a single centre population [2-5,7-10] with only one covering an entire population [6]. The data on the incidence and prevalence of AIH are summarized in Table 1.

There is also uncertainty of the impact of AIH on a patients' prognosis. Some studies have suggested that patients on corticosteroid 
Table 1

Incidence and prevalence rates of autoimmune hepatitis in selected registries.

\begin{tabular}{|c|c|c|c|c|c|}
\hline Location & Incidence/100,000 & Prevalence/100,000 & Period & Population & Reference \\
\hline Oslo, Norway & 1.9 & 16.9 & 1986-1995 & 130,000 & 2 \\
\hline Canberra, Australia & NA & 8 & NA & 525,000 & 3 \\
\hline Sourhern Israel & 0.7 & 11.0 & 1995-2010 & 910,000 & 4 \\
\hline Alaska & NA & 42.9 & 1984-2000 & 100,312 & 5 \\
\hline \multirow[t]{3}{*}{ Denmark } & 1.7 & 23.9 & 1994-2012 & $5,600,000$ & 6 \\
\hline & Women 2.4 & Women 34.6 & & & \\
\hline & Men 0.9 & Men 13.0 & & & \\
\hline \multirow[t]{3}{*}{ Valencia, Spain } & 0.8 & 11.6 & 1990-2003 & 112,003 & 7 \\
\hline & Women 1.4 & Women 19.2 & & & \\
\hline & Men 0.3 & Men 3.7 & & & \\
\hline \multirow[t]{3}{*}{ Valencia, Spain } & 1.1 & NA & 2003 & $1,774,736$ & 8 \\
\hline & Women 2.0 & & & & \\
\hline & Men 0.1 & & & & \\
\hline \multirow[t]{3}{*}{ Canterbury, New Zealand } & 2.0 & 24.5 & 2001-2008 & 494,170 & 9 \\
\hline & & Women 35.3 & & & \\
\hline & & Men 13.2 & & & \\
\hline \multirow[t]{3}{*}{ Sweden } & 0.9 & 10.7 & 1990-2003 & 715,000 & 10 \\
\hline & Women 1.2 & Women 15 & & & \\
\hline & Men 0.5 & Men 6.2 & & & \\
\hline Amsterdam, The netherlands & 1.1 & 18.3 & $1967-2011$ & 799,000 & 11 \\
\hline
\end{tabular}

NA, not available.

and/or azathioprine [12,13] have a similar survival as the general population. However, other studies have shown an impaired survival in AIH patients [6,14-17], related to pre-existing cirrhosis or uncontrolled inflammatory activity and cirrhosis development during the observation period. We have previously shown that $\mathrm{AIH}$ patients diagnosed in Finland seldom present with cirrhosis at the time of diagnosis (7\%) [18].

Clinical decisions regarding the treatment of AIH are based on knowledge of the epidemiology and the prognosis of this disease. Our aim was to collect valid data on epidemiology and survival of AIH in a nationwide population-based cohort with a long duration of follow-up.

\section{Materials and methods}

\subsection{Data sources}

In this population-based study, we gathered data from The Social Insurance Institution of Finland (SII), comprising patients with International Classification of Diseases and Related Health Problems volume 10 (ICD-10) diagnosis chronic active hepatitis K73.2 and autoimmune hepatitis K75.4, used for AIH. Every Finnish resident has a unique personal identity code (PIC), which allows the person to be identified from all official registries. Patients with certain chronic diseases, such as autoimmune hepatitis, get a reimbursement covering medical costs up to 70 percent, when the treating physician (usually a gastroenterologist, internist or a paediatrician) provides a written certificate that meets the predefined criteria for the diagnosis of the disease. These medications include corticosteroids, azathioprine, 6-mercaptopurine and cyclosporine. Prior to approval, the certificate is checked by a medical examiner, physician or a pharmacist in the SII. As a rule, the drug reimbursement is granted indefinitely. The common coverage without this special reimbursement system is 40 percent of the costs of the medication. The data from the SII covers the whole Finland. The SII data from patients living in the catchment area of Helsinki University Hospital, was cross-checked with our own hospital's AIH patients' registry to validate the data.

The time and the cause of death of the AIH patients were extracted from Statistics Finland using the PIC as the linkage key. The death certificate is written by the treating physician.

For calculations of survival, the population registry centre provided for every AIH patient five sex-matched controls with the same birth year, same age and living in Finland at the index date October 12 th, 2016.

ICD-10 was taken in use in 1995. The data were collected from 1995 to 2015 , since the ICD-10 classification was estimated to be more precise in finding AIH patients than the previous ICD codes. Special reimbursement for AIH has also been available since 1992 in Finland. We did not include patients who were granted special reimbursement for AIH prior to 1995. In December 31th, 2016, the total population of Finland was 5,503,297. There was a sharp increase in recorded cases of $\mathrm{AIH}$ in 2006, after which we saw a decline, and the incidence has remained stable after 2008. Regarding incidence, we decided to include the data after 2008. Concerning causes of death and patient survival, we used the whole data set, since there was no difference in survival in patients diagnosed prior to 2008 and thereafter.

\subsection{Statistics}

The crude incidence and prevalence rates were calculated per 100,000 person-years. The sex- and age-specific numbers were calculated according to Statistics Finland data.

Kaplan-Meier curves were used for survival. Survival hazard ratios were calculated according to Cox regression.

The numbers of observed deaths and person-years at risk were counted by sex, age and years of follow-up. The expected numbers of all causes of death combined and for specific causes of death separately were calculated by multiplying the number of person-years in each stratum by the corresponding mortality rate in inhabitants of Finland. To calculate the standardized mortality ratio (SMR), the observed number of deaths was divided by the expected number. The 95\% confidence intervals (CI) for the SMR were based on the assumption that the number of observed cases followed a Poisson distribution. Statistical computation was performed using the IBM SPSS Statistics version 24 and R environment for statistical computing and graphics (R Development Core Team 2015) using popEpi package. $\mathrm{p}<0.05$ was considered as statistically significant.

\subsection{Ethics}

Approval for the study were obtained from the Ethics committee of Internal medicine, Helsinki University Hospital (diary number 150/13/03/01/2012) and the Internal Medicine department. According to Finnish regulations, patient consent is not needed in registry studies. 


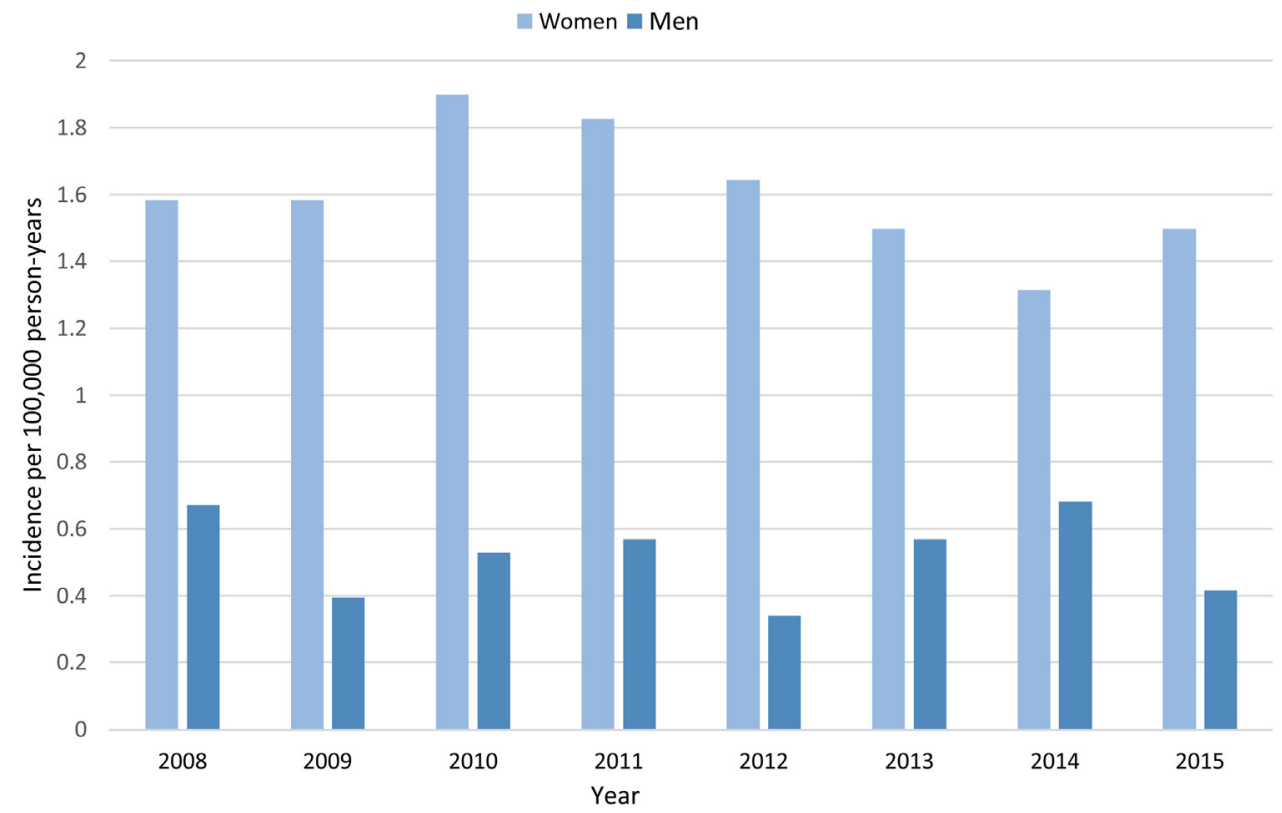

Fig. 1. Crude incidence of autoimmune hepatitis per 100,000 person-years, by year of first reimbursement.

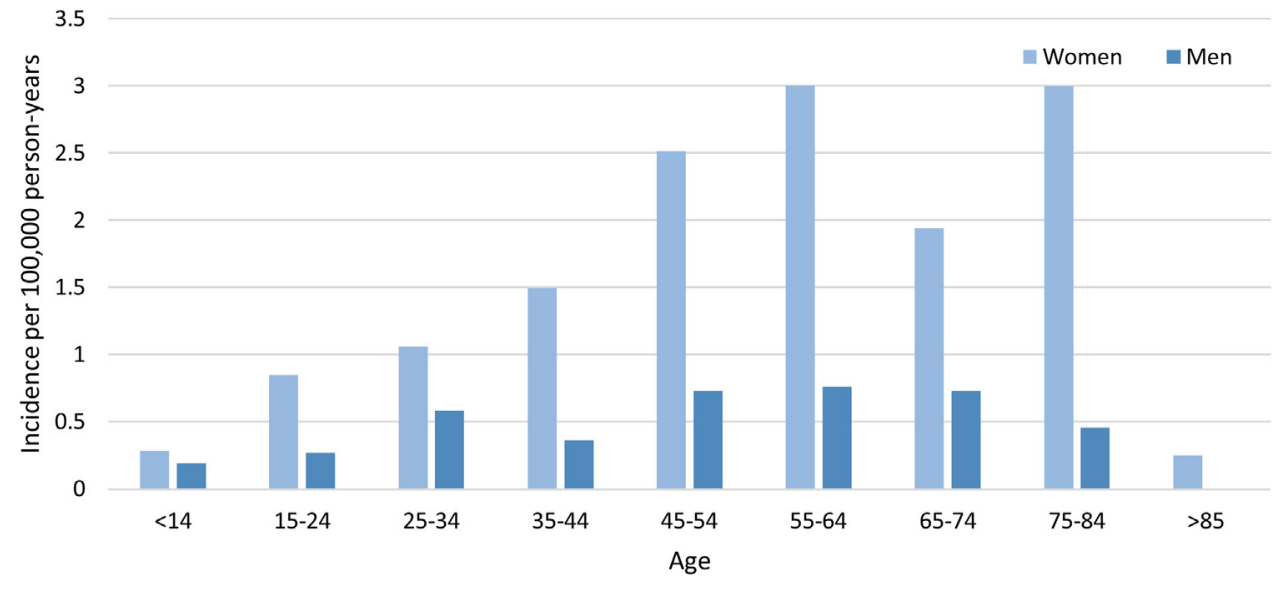

Fig. 2. Age- and sex-specific incidence rates of autoimmune hepatitis 2008-2015.

\section{Results}

\subsection{Incidence and prevalence}

The cohort consisted of $887 \mathrm{AIH}$ patients, 678 women (76\%) and 209 (24\%) men, with 6324 person-years of follow-up. In December 2016, total population of Finland was 5,503,000 and 51\% were women. The mean incidence of autoimmune hepatitis between 2008 and 2015 was 1.1/100,000/year, 1.6/100,000/year in women and $0.52 / 100,000 / y e a r$ in men. The recorded incidence 1995-2005 was $0.44 / 100,000,0.60 / 100,000$ in women and $0.22 / 100000$ in men, peaking to $1.9 / 100,000$ in 2006 and 2007 (2.9/100,000 in women and $0.89 / 100,000$ in men). Thereafter, the incidence remained stable during the study period. Incidence by year and sex is presented in Fig. 1. Age- and sex-specific incidence are presented in Fig. 2. The prevalence of autoimmune hepatitis in December 2015 was $14.3 / 100,000,23.0 / 100,000$ in women and 6.6/100,000 in men. There was a trend in increasing incidence of AIH among women with age, until a rapid decrease after age 85 . In men, there was no difference with age. The greatest portion of patients were 45-84 years old. In men, the incidence remained remarkably stable until age 75 , and there were no cases older than 75 during the whole study period (Fig. 2).

\subsection{Survival}

The survival of patients with AIH is markedly impaired compared to the age- and sex matched general population (Fig. 3). The mean 10 -year survival was $84 \%$ and twenty-year survival $76 \%$. There was no difference in patient survival between genders. During the study period, 22 (2.5\%) patients underwent liver transplantation for AIH.

\subsection{Causes of death}

Causes and number of deaths are shown in Table 3. The allcause SMR of patients with autoimmune hepatitis was 1.81 (95\% CI 1.47-2.20), with elevated SMR in all age groups (Table 2). The hazard ratio for death was 1.62 (95\% CI 1.31-2.01). The SMR was increased in all diseases studied, SMR 1.74 (95\% CI 1.40-2.14). For digestive diseases overall, SMR was 13.48 (95\% CI 8.23-20.81), constituting mainly from disease codes of AIH and liver cirrhosis. 
Table 2

All cause standardized mortality ratios in autoimmune hepatitis patients.

\begin{tabular}{|c|c|c|c|c|c|c|}
\hline & \multicolumn{2}{|c|}{ Men and women } & \multicolumn{2}{|c|}{ Women } & \multicolumn{2}{|l|}{ Men } \\
\hline & SMR & $95 \% \mathrm{CI}$ & SMR & $95 \% \mathrm{CI}$ & SMR & $95 \% \mathrm{CI}$ \\
\hline All ages & 1.81 & $1.47-2.20^{* * *}$ & 1.69 & $1.32-2.14^{* * *}$ & 2.14 & $1.44-3.04^{* * *}$ \\
\hline Age 0-29 & 6.69 & $1.38-19.55^{*}$ & 6.62 & $0.17-36.85$ & 6.73 & $0.81-24.31$ \\
\hline Age $30-59$ & 2.08 & $1.19-3.37^{*}$ & 1.88 & $0.86-3.56$ & 2.40 & $0.97-4.94$ \\
\hline Age $60+$ & 1.72 & $1.36-2.13^{* * *}$ & 1.65 & $1.26-2.12^{* * *}$ & 1.94 & $1.20-2.96^{* *}$ \\
\hline
\end{tabular}

$\mathrm{CI}$, confidence interval; SMR, standardized mortality ratio.

Table 3

Observed and expected numbers of deaths of various causes and standardized mortality ratios among Finnish AIH patients in 1995-2015.

\begin{tabular}{|c|c|c|c|c|}
\hline Cause of death & Observed & Expected & SMR & $95 \% \mathrm{CI}$ \\
\hline \multicolumn{5}{|l|}{ Men and women } \\
\hline All diseases & 89 & 51.05 & 1.74 & $1.40-2.14^{* * *}$ \\
\hline All malignant neoplasms & 27 & 15.91 & 1.70 & $1.12-2.46^{*}$ \\
\hline Hepatocellular carcinoma & 11 & 0.54 & 20.56 & $10.26-36.78^{* * *}$ \\
\hline Diseases of the digestive system (non-alcohol) & 20 & 1.48 & 13.48 & $8.23-20.81^{* * *}$ \\
\hline Liver cirrhosis & 11 & & & \\
\hline Autoimmune hepatitis & 8 & & & \\
\hline Other & 1 & & & \\
\hline \multicolumn{5}{|l|}{ Women } \\
\hline All diseases & 61 & 38.55 & 1.58 & $1.21-2.03^{* *}$ \\
\hline Hepatocellular carcinoma & 7 & 0.37 & 18.82 & $7.57-38.78^{* * *}$ \\
\hline Diseases of the respiratory system & 2 & 0.24 & 8.42 & $1.02-30.42^{*}$ \\
\hline Diseases of the digestive system (non-alcohol) & 12 & 1.18 & 10.16 & $5.25-17.74^{* * *}$ \\
\hline Liver cirrhosis & 7 & & & \\
\hline Autoimmune hepatitis & 5 & & & \\
\hline \multicolumn{5}{|l|}{ Men } \\
\hline All diseases & 28 & 12.50 & 2.24 & $1.49-3.23^{* * *}$ \\
\hline Hepatocellular carcinoma & 4 & 0.16 & 24.51 & $6.68-62.75^{* * *}$ \\
\hline Diseases of the circulatory system & 3 & 0.56 & 5.35 & $1.10-15.64^{*}$ \\
\hline Diseases of the digestive system (non-alcohol) & 8 & 0.30 & 26.41 & $11.40-52.04^{* * *}$ \\
\hline Liver cirrhosis & 3 & & & \\
\hline Autoimmune hepatitis & 4 & & & \\
\hline Other & 1 & & & \\
\hline
\end{tabular}

AIH, autoimmune hepatitis; SMR, standardized mortality ratio; $\mathrm{CI}$, confidence interval.

* $\mathrm{p}<0.05$.

** $\mathrm{p}<0.01$

$\mathrm{p}<0.001$.

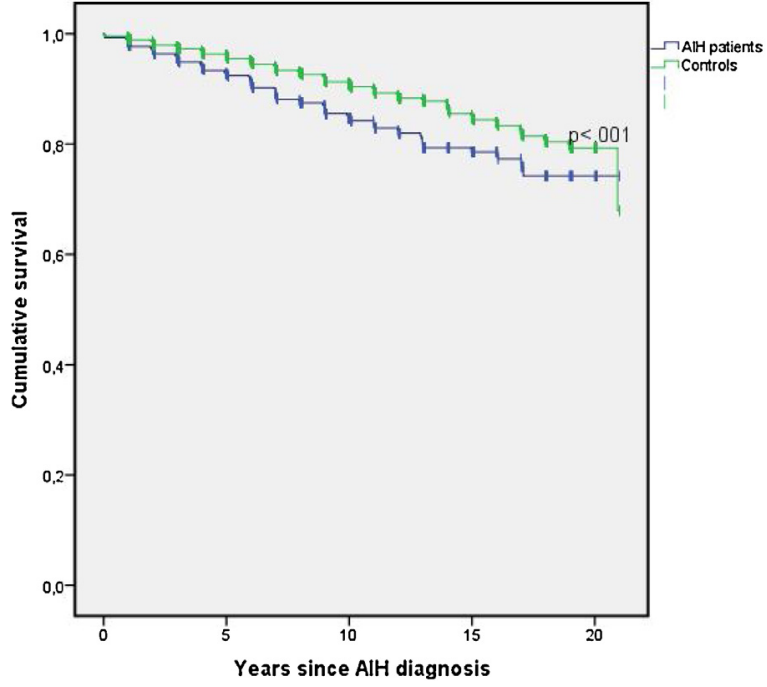

Fig. 3. Survival of autoimmune hepatitis patients diagnosed 1995-2015 compared to controls.

For hepatocellular carcinoma (HCC), the SMR was 20.56 (95\% CI 10.26-36.78). These findings were similar in both genders. There was a statistical increase in SMR for respiratory diseases in women and diseases of the cardiovascular system in men, but the overall numbers in these groups were small, and not a single disease code was dominant in these disease groups. SMR for infections, skin malignancies and lymphoid or haematological malignancies was not increased.

\section{Discussion}

In the present study we report the second largest cohort of epidemiology of autoimmune hepatitis with highest number of patient years of follow-up and with the most extensive observation period published so far. Incidence of AIH has increased from 1995 to 2015 in Finland. This trend, age and sex distribution are in line with those previously reported, 76 percent of cases occurring in women. However, in women, the incidence rose with age, and the highest portion of patients were 45-84 years of age. It has been previously reported that $\mathrm{AIH}$ is less common after age 65 or 75 [8,10,11,33]. In men, the incidence remained remarkably stable until age 75 , and there were no cases older than that in the study population. In total, only 22 patients (2.5\%) underwent liver transplantation during the study period.

AIH diagnosis may often be challenging. In clinical studies, validated scoring systems have been used [19,20]. The problem in epidemiological studies is that these criteria cannot usually reliably be retrospectively confirmed. We evaluated the Finnish hospital 
discharge registry and found 1984 cases of $\mathrm{AIH}$ in Finland during 1995-2015. In our previous study [18], only 49\% of the AIH patients in the Finnish Hospital Discharge Registry fulfilled the simplified criteria for the diagnosis of autoimmune hepatitis [20]. We believe that the AIH diagnoses in discharge registries over-estimate the incidence of $\mathrm{AIH}$. In this study, we used the drug reimbursement registry, which comprises only patients with confirmed diagnosis. SII does not routinely use validated diagnostic criteria for AIH while evaluating drug reimbursement certificates, but they still evaluate the validity of the diagnosis. This registry has been successfully used in previous studies in the field of gastroenterology and hepatology [21,22].

The incidence of AIH varied during the study years. There was an increase in the incidence along the study period, which is in concordance with what was previously reported [6].

Previous studies have shown different patterns of incidence among age groups. AIH can occur in all ages, but the bimodal agedistribution (peaks in childhood and teenage as well as in middle age) shown in earlier studies, have been challenged by more recent ones $[6,10,11]$. Autoimmune hepatitis in the elderly has also been evaluated in two studies [23,24], which showed that AIH in the elderly has a similar phenotype as in younger patients. It has previously been reported that AIH is less common after age 65 or 75 $[8,10,11,33]$. The sex ratio has been similar as in previous studies, men comprising $25-30 \%$ of the population affected $[5,6,10,11]$.

The overall mortality of patients with $\mathrm{AIH}$ was elevated; the SMR was 2.14 in men and 1.69 in women. The high SMR as mainly explained by hepatocellular carcinoma, liver cirrhosis and autoimmune hepatitis per se. Table 3 shows, that there are 38 cases of excess death in AIH patients (89 observed and 51 expected). 11 of them are HCC, $8 \mathrm{AIH}$ and 11 cirrhosis constituting 30 cases of these 38. These are listed as primary causes of death. We do not know the exact reason for death, but probably they are part of the same continuum of AIH progressing to cirrhosis. Unfortunately, our data reports cirrhosis only when it is listed as the primary cause of death. The proportion of cirrhotic patients would be important to know because HCC is thought to develop only in cirrhotic AIH. Higher mortality due to hepatic malignancies is a conundrum since hepatic malignancies are known to be associated with advanced liver disease, as well as immunosuppressive therapy [6,25-28]. We did not find any increased mortality risk for lymphomas, infections or skin cancers, including melanoma, which have been reported to be increased in patients on immunosuppressive therapy [29-32]. In earlier studies, conflicting results have been reported on the survival of AIH patients. Our study on a large nationwide population with the longest follow-up so far clearly demonstrates that there is a constant increase in the risk of death already from the time of diagnosis. This was an unexpected finding, as we have previously shown that patients in Finland are more often non-cirrhotic at the time of diagnosis than reported in earlier studies. It has been suggested that it is not AIH as such, but merely the cirrhosis leading in decreased survival, as proposed by earlier studies [6,12-17].

In conclusion, we have demonstrated that the incidence and prevalence of AIH have remained stable after 2008 in Finland, in this second largest cohort with the longest follow-up. Short- and longterm prognosis in AIH patients is markedly impaired compared to that of the general population, mainly due to hepatocellular carcinoma and liver cirrhosis. Despite the improved follow-up methods and treatment options, including new medications and liver transplantation, AIH is still associated with a significantly decreased life expectancy. The markedly increased risk of hepatocellular cancer underlines the importance of early detection of cirrhosis and systematic surveillance of AIH patients for HCC.

\section{Conflicts of interest}

None declared.

\section{References}

[1] Czaja AJ, Freese DK, American Association for the Study of Liver D. Diagnosis and treatment of autoimmune hepatitis. Hepatology (Baltimore, Md) 2002;36:479-97.

[2] Boberg KM, Aadland E, Jahnsen J, Raknerud N, Stiris M, Bell H. Incidence and prevalence of primary biliary cirrhosis, primary sclerosing cholangitis, and autoimmune hepatitis in a Norwegian population. Scand J Gastroenterol 1998;33:99-103.

[3] Haider AS, Kaye G, Thomson A. Autoimmune hepatitis in a demographically isolated area of Australia. Int Med J 2010;40:281-5.

[4] Delgado JS, Vodonos A, Malnick S, Kriger O, Wilkof-Segev R, Delgado B, et al. Autoimmune hepatitis in southern Israel: a 15-year multicenter study. J Dig Dis 2013;14:611-8.

[5] Hurlburt KJ, McMahon BJ, Deubner H, Hsu-Trawinski B, Williams JL, Kowdley KV. Prevalence of autoimmune liver disease in Alaska Natives. Am J Gastroenterol 2002;97:2402-7

[6] Gronbaek L, Vilstrup H, Jepsen P. Autoimmune hepatitis in Denmark: incidence, prevalence, prognosis, and causes of death. A nationwide registry-based cohort study. J Hepatol 2014;60:612-7.

[7] Primo J, Merino C, Fernandez J, Moles JR, Llorca P, Hinojosa J. [Incidence and prevalence of autoimmune hepatitis in the area of the Hospital de Sagunto (Spain)]. Gastroenterologia y hepatologia 2004;27:239-43.

[8] Primo J, Maroto N, Martinez M, Anton MD, Zaragoza A, Giner R, et al. Incidence of adult form of autoimmune hepatitis in Valencia (Spain). Acta Gastroenterol Belg 2009;72:402-6.

[9] Ngu JH, Gearry RB, Frampton CM, Stedman CA. Predictors of poor outcome in patients w ith autoimmune hepatitis: a population-based study. Hepatology (Baltimore, Md) 2013;57:2399-406.

[10] Werner M, Prytz H, Ohlsson B, Almer S, Bjornsson E, Bergquist A, et al. Epidemiology and the initial presentation of autoimmune hepatitis in Sweden: a nationwide study. Scand J Gastroenterol 2008;43:1232-40.

[11] van Gerven NM, Verwer BJ, Witte BI, van Erpecum KJ, van Buuren HR, Maijers I, et al. Epidemiology and clinical characteristics of autoimmune hepatitis in the Netherlands. Scand J Gastroenterol 2014;49:1245-54.

[12] Feld JJ, Dinh H, Arenovich T, Marcus VA, Wanless IR, Heathcote EJ. Autoimmune hepatitis: effect of symptoms and cirrhosis on natural history and outcome. Hepatology (Baltimore, Md) 2005;42:53-62.

[13] Yoshizawa K, Matsumoto A, Ichijo T, Umemura T, Joshita S, Komatsu M, et al. Long-term outcome of Japanese patients with type 1 autoimmune hepatitis. Hepatology 2012;56:668-76.

[14] Dhaliwal HK, Hoeroldt BS, Dube AK, McFarlane E, Underwood JC, Karajeh $\mathrm{MA}$, et al. Long-term prognostic significance of persisting histological activity despite biochemical remission in autoimmune hepatitis. Am J Gastroenterol 2015;110:993-9.

[15] Hoeroldt B, McFarlane E, Dube A, Basumani P, Karajeh M, Campbell MJ, et al. Long-term outcomes of patients with autoimmune hepatitis managed at a nontransplant center. Gastroenterology 2011;140:1980-9.

[16] Kirstein MM, Metzler F, Geiger E, Heinrich E, Hallensleben M, Manns MP, et al. Prediction of short- and long-term outcome in patients with autoimmune hepatitis. Hepatology (Baltimore, Md) 2015;62:1524-35.

[17] Landeira G, Morise S, Fassio E, Ramonet M, Alvarez E, Caglio P, et al. Effect of cirrhosis at baseline on the outcome of type 1 autoimmune hepatitis. Ann Hepatol 2012;11:100-6.

[18] Puustinen L, Boyd S, Mustonen H, Arkkila P, Arola J, Farkkila M. Prognostic value of clinical variables and liver histology for development of fibrosis and cirrhosis in autoimmune hepatitis. Scand J Gastroenterol 2017;52:321-7.

[19] Alvarez F, Berg PA, Bianchi FB, Bianchi L, Burroughs AK, Cancado EL, et al. International Autoimmune Hepatitis Group Report: review of criteria for diagnosis of autoimmune hepatitis. J Hepatol 1999;31:929-38.

[20] Hennes EM, Zeniya M, Czaja AJ, Pares A, Dalekos GN, Krawitt EL, et al. Simplified criteria for the diagnosis of autoimmune hepatitis. Hepatology (Baltimore, Md) 2008;48:169-76.

[21] Jussila A, Virta LJ, Kautiainen H, Rekiaro M, Nieminen U, Farkkila MA. Increasing incidence of inflammatory bowel diseases between 2000 and 2007: a nationwide register study in Finland. Inflamm Bowel Dis 2012;18:555-61.

[22] Turunen P, Kolho KL, Auvinen A, Iltanen S, Huhtala H, Ashorn M. Incidence of inflammatory bowel disease in Finnish children, 1987-2003. Inflamm Bowel Dis 2006;12:677-83.

[23] Schramm C, Kanzler S, zum Buschenfelde KH, Galle PR, Lohse AW. Autoimmune hepatitis in the elderly. Am J Gastroenterol 2001;96:1587-91.

[24] Al-Chalabi T, Boccato S, Portmann BC, McFarlane IG, Heneghan MA. Autoimmune hepatitis $(\mathrm{AIH})$ in the elderly: a systematic retrospective analysis of a large group of consecutive patients with definite $\mathrm{AIH}$ followed at a tertiary referral centre. J Hepatol 2006;45:575-83.

[25] Wong RJ, Gish R, Frederick T, Bzowej N, Frenette C. Development of hepatocellular carcinoma in autoimmune hepatitis patients: a case series. Dig Dis Sci 2011;56:578-85.

[26] Montano-Loza AJ, Carpenter HA, Czaja AJ. Predictive factors for hepatocellular carcinoma in type 1 autoimmune hepatitis. A J Gastroenterol 2008; 103:1944-51.

[27] Penn I. Depressed immunity and the development of cancer. Cancer Detect Prev 1994;18:241-52.

[28] Izumi S, Nakamura S, Mano S. Large intrahepatic cholangiocarcinoma with tumor infiltrative lymphocytes and autoimmune hepatitis-Like features. Case Rep Gastroenterol 2010;4:46-51. 
[29] Aguilar HI, Burgart LJ, Geller A, et al. Azathioprine-induced lymphoma manifesting as fulminant hepatic failure. Mayo Clin Proc 1997;72:643-5.

[30] Wang KK, Czaja AJ, Beaver SJ, et al. Extrahepatic malignancy following long-term immunosuppressive therapy of severe hepatitis B surface antigennegative chronic active hepatitis. Hepatology 1989;10:39-43.
[31] Frezza EE, Fung J, van Thiel DH. Non-lymphoid cancer after liver transplantation. Hepatogastroenterology 1997;44:1172-81.

[32] Connell WR, Kamm MA, Ritchie JK, et al. Bone marrow toxicity caused by azathioprine in inflammatory bowel disease: 27 years of experience. Gut 1993;34:1081-5.

Please cite this article in press as: Puustinen L, et al. Incidence, prevalence, and causes of death of patients with autoimmune hepatitis: A nationwide register-based cohort study in Finland. Dig Liver Dis (2019), https://doi.org/10.1016/j.dld.2019.01.015 